\title{
Dificuldades enfrentadas pelos professores da Educação de Jovens e Adultos de um município do interior de Mato Grosso
}

Difficulties faced by teachers of Youth and Adult Education in a municipality in the interior of Mato Grosso

Dificultades que enfrentan los docentes de Educación de Jóvenes y Adultos en un municipio del interior de Mato Grosso

Leilane Alves de Oliveira

ORCID: https://orcid.org/0000-0001-6002-5451 Universidade Federal de Mato Grosso, Brasil E-mail: Leilanyalves88@gmail.com

Felício Guilardi Junior

ORCID: https://orcid.org/0000-0002-1859-3217

Universidade Federal de Mato Grosso, Brasi E-mail: fifo2801@gmail.comr

Julio Martinez Alves Oliveira

ORCID: https://orcid.org/0000-0002-3173-9444 Universidade Estadual Paulista "Júlio de Mesquita Filho", Brasil E-mail: juliooliveira1994@hotmail.com

Jéssica Alves de Oliveira

ORCID: https://orcid.org/0000-0003-0866-5448 Universidade Federal de Mato Grosso, Brasil E-mail: jessicaavufmt@hotmail.com

Rosângela Aparecida Alves Martinez de Oliveira

ORCID: https://orcid.org/0000-0003-2376-8963

Universidade Estadual de Mato Grosso, Brasil E-mail: martinezroseol@ hotmail.com

Pedro Henrique Petrilli

ORCID: https://orcid.org/0000-0003-2011-1851 Universidade Estadual Paulista “Júlio de Mesquita Filho", Brasil E-mail: pedropetrilli@gmail.com

Tânia Adas Saliba

ORCID: https://orcid.org/0000 0003-1327-2913 Universidade Estadual Paulista "Júlio de Mesquita Filho", Brasil E-mail: tania.saliba@unesp.br

\begin{abstract}
Resumo
Este trabalho foi realizado na escola em uma escola pública de Sinop,Mato Grosso, Brasil, no ano de 2011 e tem como objetivo identificar como se desenvolve o processo de ensino e aprendizagem e os problemas enfrentados pelos docentes. Para isso, foi feito pesquisa bibliográfica e de campo com uma amostra de professores e alunos que lecionam e frequentam, respectivamente a escola, sendo aplicados questionários com perguntas abertas e fechadas. As informações obtidas a partir desse levantamento, forneceram dados sobre os reais problemas presentes na Educação de Jovens e Adultos. Através dos questionários aplicados aos alunos constatou-se que 57\% pertencem ao sexo feminino e $43 \%$ pertencem ao sexo masculino. Ao questionar os alunos quanto ao motivo que os levou a não mais frequentar o Ensino Regular, o maior índice foi de $44,44 \%$ para ter que ajudar economicamente a família, seguido de $30,30 \%$ desistiram da escola regular devido a problemas familiares, $18,18 \%$ outros motivos, $4,04 \%$ não responderam, $2,02 \%$ foi devido à reprovação escolar, $1,01 \%$ não parou de estudar. Dos motivos que levaram os alunos entrevistados a voltar a estudar, obteve-se o maior índice a realização pessoal que ficou com $44,44 \%$, seguido por $35,35 \%$ que pretendem adquirir um emprego, 12,12\% outros motivos, 7,07\% permanecer no emprego, 1,01\% preferiu não responder. A partir das respostas, conclui-se que a escola CEJA SILVA FREIRE, busca atender os alunos respeitando sua cultura e história de vida.
\end{abstract}

Palavras-chave: Educação de jovens e adultos; Ensino; Aprendizagem. 


\begin{abstract}
This work was carried out at school in a public school in Sinop, Mato Grosso, Brazil, in 2011 and aims to identify how the process of development develops. teaching and learning and the problems faced by teachers. For this, bibliographic and field research was carried out with a sample of teachers and students who teach and attend school, respectively, and questionnaires with open and closed questions were applied. The information obtained from this survey, provided data on the real problems present in Youth and Adult Education. Through the questionnaires applied to the students it was found that $57 \%$ belong to the female sex and $43 \%$ belong to the male sex. When questioning students as to why they no longer attended regular education, the highest rate was $44.44 \%$ for having to help the family economically, followed by $30.30 \%$ quitting regular school due to family problems, $18.18 \%$ other reasons, 4.04\% did not answer, $2.02 \%$ was due to school failure, $1.01 \%$ did not stop studying. Of the reasons that led the interviewed students to return to study, the highest index was the personal achievement, which was $44.44 \%$, followed by $35.35 \%$ who intend to acquire a job, $12.12 \%$ other reasons, $7,07 \%$ remain in employment, $1.01 \%$ chose not to respond. From the answers, it is concluded that the CEJA SILVA FREIRE school seeks to serve students respecting their culture and life history.
\end{abstract}

Keywords: Youth and adult education; Teaching; Learning.

\title{
Resumen
}

Este trabajo fue realizado en la escuela de una escuela pública de Sinop, Mato Grosso, Brasil, en 2011 y tiene como objetivo identificar cómo se desarrolla el proceso de desarrollo. el aprendizaje y los problemas que enfrentan los profesores. Para ello, se realizó una investigación bibliográfica y de campo con una muestra de docentes y alumnos que imparten clases y asisten a la escuela, respectivamente, y se aplicaron cuestionarios con preguntas abiertas y cerradas. La información obtenida de esta encuesta, proporcionó datos sobre los problemas reales presentes en la Educación de Jóvenes y Adultos. A través de los cuestionarios aplicados a los estudiantes se encontró que el $57 \%$ pertenecen al sexo femenino y el $43 \%$ pertenecen al sexo masculino. Al cuestionar a los estudiantes por qué ya no asistían a la educación regular, la tasa más alta fue de $44,44 \%$ por tener que ayudar económicamente a la familia, seguido de 30,30\% que abandonó la escuela regular por problemas familiares, $18,18 \%$ otras razones, $4,04 \%$ no respondió, El 2,02\% se debió al fracaso escolar, el 1,01\% no dejó de estudiar. De los motivos que llevaron a los estudiantes entrevistados a volver a estudiar, el índice más alto fue el logro personal, que fue de 44,44\%, seguido de $35,35 \%$ que pretenden adquirir un empleo, 12,12\% otros motivos, 7,07\% permanecen en el empleo, El 1,01\% optó por no responder. De las respuestas se concluye que el colegio CEJA SILVA FREIRE busca atender a los alumnos respetando su cultura e historia de vida.

Palabras clave: Aprendizaje de jóvenes y adultos; Educación; Enseñanza.

\section{Introdução}

Estamos vivendo em um mundo cada vez mais acelerado e de mudanças profundas nos campos tecnológicos, econômico, cultural, social e educacional. Precisamos acompanhar essas transformações e evoluções que estão acontecendo. (Cardoso, 2007)

O mercado de trabalho está cada vez mais diversificado e amplamente concorrido necessitando de profissionais qualificados para atuar em diversos setores do mercado. Com essas mudanças, o trabalhador busca se adaptar as inovações buscando qualificação profissional. (Becker, 2012)

Diante dessas situações, muitas pessoas voltam a estudar com objetivo de buscar conhecimentos e qualificação profissional. Essas pessoas, geralmente, não possuem o ensino fundamental ou ensino médio e buscam a EJA (Educação de jovens e adultos) para concluir os estudos básicos.

De acordo com Nascimento (2013) a educação de jovens e adultos (EJA), é uma modalidade do ensino fundamental e do ensino médio, que oferece acesso ao conhecimento científico para aquelas pessoas que não tiveram oportunidade de continuar seus estudos e assim garantindo direitos aos que foram excluídos do cenário escolar ou que não tiveram oportunidade de estudar.

A educação de jovens e adultos atende alunos com idade superior de estudantes do ensino regular, pois são pessoas que não conseguiram concluir os estudos na idade estabelecida. As salas de aulas são compostas por um grupo heterogêneo de estudantes, com diferentes faixas etárias, e diferentes expectativas. 
Através deste trabalho, o objetivo foi compreender as especificidades do processo de Educação de Jovens e Adultos por quem exerce efetivamente a docência no CEJA e como se desenvolve o processo de ensino e aprendizagem e identificar os problemas enfrentados pelos docentes.

\section{Metodologia}

O trabalho foi desenvolvido na Escola Estadual CEJA SILVA FREIRE localizada na Rua das Avencas, ${ }^{\circ}$ 800, centro de Sinop, Mato Grosso, Brasil.

De acordo com o Projeto Político Pedagógico (PPP) a proposta pedagógica da escola CEJA SILVA FREIRE está fundamentada nos pressupostos teóricos de Paulo Freire, Levy S. Vygotsky e Emília Ferrero.

Para Barbosa et al. (2006) com o objetivo de buscar mais conhecimentos, o pesquisador desenvolve hábitos para aprender através da pesquisa. Para isso é importante observar, selecionar, organizar e usar a criticidade sobre a realidade do mundo que nos cerca.

Nos métodos quantitativos, faz-se a coleta de dados quantitativos ou numéricos por meio do uso de medições de grandezas e obtém-se por meio da metrologia, números com suas respectivas unidades. (Pereira et al., 2018). Este estudo tem como característica uma pesquisa bibliográfica de caráter descritivo, constituído através de uma abordagem quantitativa e qualitativa para descrever detalhes das situações.

$\mathrm{Na}$ pesquisa foi utilizado questionários com professores estruturado com 14 questões intercaladas entre objetivas e subjetivas e questionários aplicados aos estudantes com 8 questões intercaladas entre objetivas e subjetivas do CEJA Sinop / MT, com o intuito de diagnosticar as dificuldades encontradas pelos professores Centro de Educação de Jovens e Adultos, para melhor compreensão da realidade escolar. O trabalho foi desenvolvido na Escola Estadual CEJA SILVA FREIRE (Figura 1), localizada na Rua das Avencas, $n^{\circ} 800$, centro.

Ao todo foram entrevistados 99 estudantes matriculados no CEJA do Ensino Fundamental e Médio, e 8 professores do CEJA das áreas de ciências humanas, linguagens e ciências naturais. As respostas dos entrevistados foram representadas em gráficos e tabelas, com intuito de apresentar maior clareza na apresentação dos dados que foram coletados.

\section{Resultados e Discussões}

Segundo Freire (1996), "A leitura do mundo precede a leitura da palavra". Nesse sentido, o educando chega a escola com a "leitura de mundo" condicionada por sua cultura de classe que também é revelada em sua linguagem de classe, se constitui em um obstáculo à sua experiência de conhecimento. O educador precisa respeitar a leitura de mundo do educando, pois é a maneira correta que tem o educador de, com o educando e não sobre ele, superando a maneira ingênua por outra mais crítica de compreender o mundo.

De acordo com o PPP do CEJA, são oferecidas aulas complementares aos alunos como oficinas pedagógicas, plantão, aulas culturais que serão detalhadas abaixo:

As oficinas pedagógicas têm como objetivo trabalhar as dificuldades na construção do conhecimento encontradas nas aulas da turma de origem, através da utilização de mapas conceituais, jogos, aulas práticas, construção de portfólio.

Os plantões, que são feitos individualizados, contempla uma relação pedagógica personalizada, respeitando o ritmo próprio do educando. Isto é organizado através de um cronograma que estipula o período, dias e horários de aula.

As aulas culturais são feitas através de festivais, gincanas, seminários, metodologia de projetos, são atividades transdisciplinares unindo todas as áreas do conhecimento, num processo voltado para a compreensão da realidade. 
Programa Institucional de Bolsa de Iniciação à Docência (PIBID) é um programa constituído para a melhoria do processo formativo de estudantes dos cursos de licenciatura, e possibilita que as pesquisas acadêmicas cheguem às salas de aula. Os acadêmicos do PIBID da UFMT participaram com algumas atividades na escola CEJA Silva Freire. Essas atividades foram realizadas através de experimentos com os alunos para proporcionar melhor entendimento do conteúdo.

Através dos questionários aplicados aos alunos constatou-se que 57\% pertencem ao sexo feminino e $43 \%$ pertencem ao sexo masculino. Estes dados demonstram que a Educação de Jovens e Adultos apresenta-se como um espaço sem distinção de gênero. Estes dados podem ser observados no Gráfico 1:

Gráfico 1: Dados relativos ao gênero dos estudantes em entrevistados do CEJA de Sinop - MT (2011).

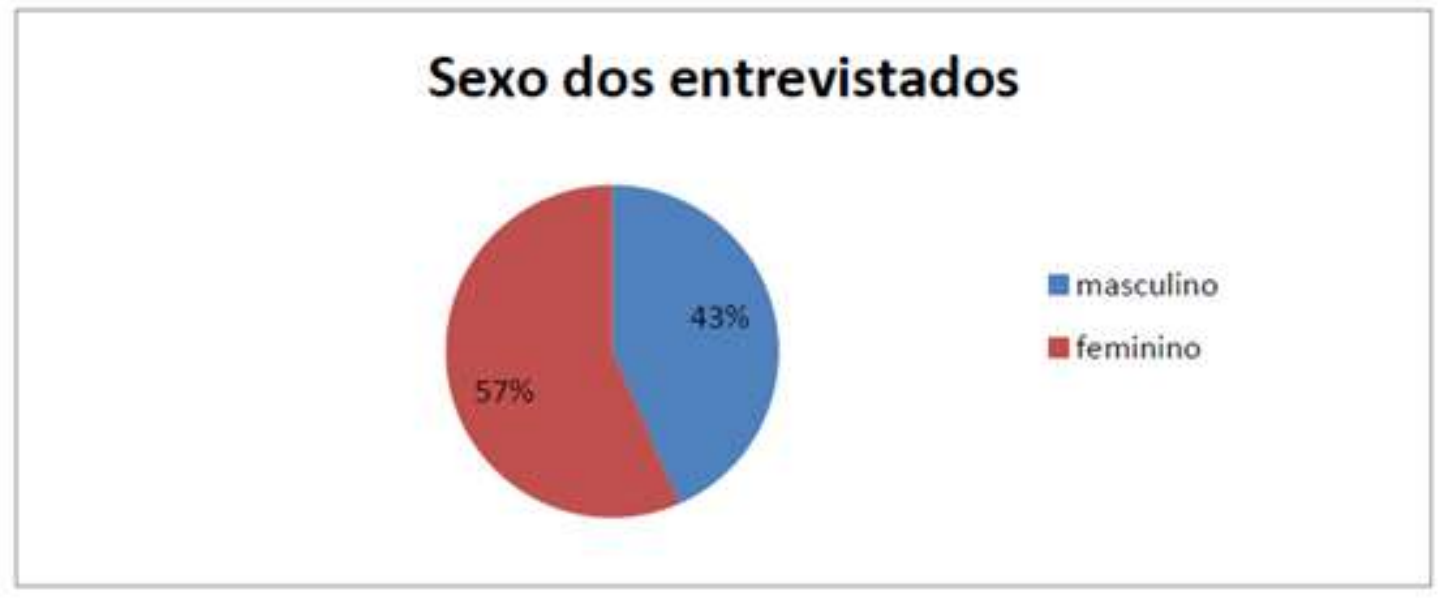

Fonte: Gráfico organizado pelos autores.

Segundo a Tabela 1, 83,84\% dos estudantes entrevistados frequentam o Ensino Fundamental e 16,16\% frequentam o Ensino Médio. Estes dados são apresentados na tabela a seguir:

Tabela 1: Nível que frequenta.

\begin{tabular}{ccc}
\hline NIVEL QUE & NÚMERO DE ALUNOS & PORCENTAGEM \\
FREQUENTA & & $\%$ \\
\hline Ensino Fundamental & 83 & 83,84 \\
Ensino Médio & 16 & 16,16 \\
TOTAL & 99 & 100 \\
\hline
\end{tabular}

Fonte: Tabela organizada pelos autores.

Ao questionar os alunos quanto ao motivo que os levou a não mais frequentar o Ensino Regular, o maior índice foi de 44,44\% para ter que ajudar economicamente a família, seguido de 30,30\% desistiram da escola regular devido a problemas familiares, $18,18 \%$ outros motivos, $4,04 \%$ não responderam, $2,02 \%$ foi devido à reprovação escolar, $1,01 \%$ não parou de estudar. Estes dados estão especificados na Tabela 2: 
Tabela 2: Motivos que desistiu de frequentar a escola regular.

\begin{tabular}{cccc}
\hline MOTIVOS QUE DESISTIU DE & TOTAL & DE & PORCENTAGEM \\
FREQUEENTAR A ESCOLA REGULAR & ESTUDANTES & \\
\hline Ajudar economicamente a familia & 44 & 44.44 \\
Problemas familiares & 30 & 30.30 \\
Outros & 18 & 18,18 \\
Não responderam & 04 & 4.04 \\
Reprovação escolar & 02 & 2.02 \\
Não parou de estudar & 01 & 1,01 \\
TOTAL & 99 & 100 \\
\hline
\end{tabular}

Fonte: Tabela organizada pelos autores

De acordo com a tabela, fatores como ajudar família economicamente em casa, problemas familiares, reprovação escolar, contribuem para que o aluno desista de estudar.

Conforme AJALA (2011) muitos estudos relatam que um dos principais fatores que levam ao abandono escolar está relacionado ao trabalho fora de casa. De acordo com Inocêncio et al. (2017) a reprovação, é um fator que contribui para que o aluno deixe a escola, pois fica desmotivado e não acreditando em si mesmo, aceitando a ideia que não possui condições de passar para o ano seguinte.

Dos motivos que levaram os alunos entrevistados a voltar a estudar, obteve-se o maior índice a realização pessoal que ficou com $44,44 \%$, seguido por $35,35 \%$ que pretendem adquirir um emprego, $12,12 \%$ outros motivos, $7,07 \%$ permanecer no emprego, 1,01\% preferiu não responder. Estes dados são representados na tabela a seguir:

Tabela 3: Motivos que levaram os estudantes a voltar a estudar.

\begin{tabular}{lcc}
\hline \multicolumn{1}{c}{$\begin{array}{c}\text { MOTIVOS QUE } \\
\text { LEVARAM ALUNOS A } \\
\text { VOLTAR A ESTUDAR }\end{array}$} & NUMERO DE ALUNOS & $\begin{array}{c}\text { PORCENTAGEM } \\
(\%)\end{array}$ \\
\hline Realizaço pessoal & & 44.44 \\
\hline Adquirir um emprego & 44 & 35.35 \\
Outros motivos & 35 & 12.12 \\
Permanecer no emprego & 12 & 7.07 \\
Não respondeu & 7 & 1.01 \\
\multicolumn{1}{c}{ TOTAL } & 1 & 100.00 \\
\hline
\end{tabular}

Fonte: Tabela organizada pelos autores.

Os motivos que levaram os alunos voltarem à estudar estão relacionados à realização pessoal, adquirir um emprego, maior qualificação para permanecer no emprego.

Muitos alunos retornam à escola para adquirir realização pessoal, o sonho de concluir o ensino médio, e em seguida preparação para curso superior ou técnico buscando maior qualificação para o mercado de trabalho e assim adquirir um emprego melhor ou até mesmo permanecer no trabalho de forma mais qualificado.

De acordo com Guerra et al. (2014) os educandos com mais oportunidades, aliam seus sonhos com objetivos de vida, e com determinação enfrentam as barreiras que estão impedindo seu crescimento e independência, buscando conhecimento e dias melhores.

Com relação a principal dificuldade que os alunos questionados sentem em adquirir o conhecimento, o maior índice ficou em torno da falta de tempo para estudar com 36,36\%, com 29,29\%, devido há muito tempo longe da Escola, 24,24\% 
trabalha muito e quase não tem tempo para estudar, 9,09\% outros motivos, 1,01\% preferiu não responder. Estes dados foram seguidos por outros que serão explicitados na tabela abaixo:

Tabela 4 - Dificuldades ao adquirir conhecimento.

\begin{tabular}{ccc}
\hline $\begin{array}{c}\text { DIFICULDADES AO } \\
\text { ADQUIRIR } \\
\text { CONHECIMENTO }\end{array}$ & NUMERO DE ALUNOS & $\begin{array}{c}\text { PORCENTAGEM } \\
(\%)\end{array}$ \\
\hline $\begin{array}{c}\text { Falta de tempo para } \\
\text { estudar }\end{array}$ & 36 & 36,36 \\
\hline $\begin{array}{c}\text { Muito tempo fora da } \\
\text { escola }\end{array}$ & 29 & 29,29 \\
Trabalha muito & 24 & 24,24 \\
\hline $\begin{array}{c}\text { Outros motivos } \\
\text { Nào respondeu }\end{array}$ & 9 & 9,09 \\
\hline TOTAL & 1 & 1,01 \\
\hline
\end{tabular}

Fonte: Tabela organizada pelos autores.

As maiores dificuldades em adquirir conhecimentos são em relação a falta de tempo, muito tempo fora da escola, e carga horária elevada de trabalho. Segundo CARBONE (2013) “a canseira diária, problemas cotidianos são fatores que afetam no processo de desenvolvimento de aprendizagem, e pode interferir na permanência do aluno na escola. Os estudantes mais velhos possuem maiores dificuldades em assimilar os conteúdos, principalmente no que diz respeito à alfabetização e ao letramento. Muitos conseguem decodificar o código escrito, mas não conseguem fazer interpretação, são os chamados de analfabetos funcionais."

Os questionários aplicados aos 8 professores que trabalham no CEJA, foram analisados e serão discutidos neste momento da pesquisa.

Todos os professores responderam que possuem conhecimento do Projeto Político e Pedagógico do CEJA. Em relação aos objetivos e estratégias de ensino que orientam as ações didáticas pedagógicas, a maioria respondeu que é importante reconhecer as especificidades dos sujeitos do CEJA e dos diferentes tempos e espaços formativos, oferecendo formas diferenciadas de atendimento que compreendam a educação formal, informal integrada ao mundo do trabalho ao longo da vida. Buscar a aprendizagem significativa, trabalhando os conteúdos voltados a sua realidade profissional e formal. A aprendizagem deve ser significativa relacionando os conteúdos trabalhados a vivência dos alunos. As atividades propostas devem favorecer o desenvolvimento do raciocínio lógico, elaboração de hipóteses e busca de soluções. Formar cidadão político social e economicamente ativo, elevando o nível de escolaridade com metodologia específica para ter igualdade de acesso ao mercado de trabalho.

$\mathrm{Na}$ pergunta que especificidades devem ser consideradas na Educação de Jovens e Adultos em relação ao ensino regular a maioria respondeu que se deve considerar a diferença de idade entre alunos em uma mesma turma, tempo de afastamento da escola, responsabilidade que possuem em relação a trabalho e família, distância de sua residência até a escola, sua história, conhecimentos prévio, déficit de aprendizagem, diferentes tempos de aprendizagem de cada aluno. Além disso, há que se ter tolerância com relação a horários, entrega de trabalho e ritmos de aprendizagem.

Ao questionar quais fundamentos teóricos e metodológicos orientam a educação de jovens e adultos os professores responderam de maneira geral uma busca de identidade metodológica voltada, principalmente, às teorias de Paulo Freire, Levy Vigotsky, Emília Ferrero, busca de interdisciplinaridade, trabalho com projetos e temas geradores, aulas teóricas, oficinas pedagógicas e plantões, levar em consideração o conhecimento prévio do aluno. 
Em relação aos recursos didáticos considerados importantes para a aprendizagem dos alunos, eles responderam que consideram importantes os recursos tecnológicos (computadores, televisão, etc), livros didáticos, materiais apostilados, dicionários, mapas, globo terrestre, jornais, revistas, multimídia, recurso visual (quadro), jogos, oficinas. Também é importante trabalhar com materiais concretos para aulas práticas, trabalhar com a realidade.

Ao questionar se além dos livros didáticos são utilizados outros recursos, eles responderam que usam mapas, filmes, documentários, textos (revistas, jornais) para leitura, reflexão e debates, apostilas, data show, experimentos, slides, multimídia.

Ao perguntar aos professores entrevistados se o material didático que eles utilizam está coerente com a realidade de seus alunos a maioria respondeu que sim e apenas três deles disse que não está coerente com a realidade dos mesmos. Os que responderam que sim, argumentaram que a escola disponibiliza equipamentos e materiais didáticos suficientes para que o trabalho seja desenvolvido. Os que responderam que o material didático não está coerente com a realidade dos alunos, argumentando que os livros disponíveis não contemplam o conteúdo programático na íntegra, o material é muito pobre em conhecimento.

Ao questionar qual a maior dificuldade enfrentada pelos alunos do CEJA, eles responderam que as dificuldades são inúmeras, como leitura, interpretação de textos, alfabetização precária, alguns anos fora da sala de aula, as diferenças de idade, falta de conhecimentos prévios, falta de materiais didáticos apropriados. O cansaço é um dos fatores que muito prejudica o desenvolvimento dos trabalhos, principalmente, os alunos do noturno que em geral trabalham em serviços pesados e com horários prolongados. Em função disso, faltam muito ou vão para casa mais cedo perdendo a continuidade do trabalho, do rendimento escolar. Conciliar trabalho com estudos é algo que exige muito esforço e dedicação.

Sobre a pergunta se participou do projeto de desenvolvimento de oficinas pedagógicas e qual importância atribui a esta. Somente um dos entrevistados não participou, e os que participaram responderam que é importante, pois contribui para a compreensão da teoria e trazem um aprofundamento do conteúdo trabalhado em sala de aula.

Ao perguntar quais sugestões para que as oficinas realizadas pelos acadêmicos da UFMT através do PIBID, proporcionando referência à realidade imediata dos alunos, eles responderam que é importante a realização de oficinas atraentes para os alunos e de preferência que contemple o conteúdo com alguma prática de fácil entendimento e que tenha a ver com a realidade. As oficinas devem ser vinculadas com os conteúdos programáticos juntamente com o professor da disciplina.

A última questão foi baseada na frase de Paulo Freire: "A leitura do mundo precede a leitura da palavra", neste sentido foi perguntado aos professores em que consiste um ensino que considere os sujeitos do conhecimento como ativos e não passivos, ao se considerar que possuem leituras do mundo diferenciadas de concepções a serem desenvolvidas no ambiente escolar. Eles responderam que é muito importante considerar o conhecimento prévio do aluno, sua forma de pensar e tentar relacionar o conteúdo a sua realidade. Deve considerar os conhecimentos, história de cada aluno, antes mesmo de desenvolver os conteúdos escolares.

Todas as pessoas adquirem conhecimentos nas experiências de vida. $\mathrm{O}$ adulto, com certeza conhece muitas coisas que não são do domínio do professor, mas que podem contribuir para que toda a turma cresça. A função do professor é contribuir para que estudante construa o conhecimento.

\section{Conclusão}

O trabalho teve como ponto de partida, buscar compreender tais relações no centro de educação de jovens e adultos no município de Sinop, para entender como se desenvolve o processo de ensino e aprendizagem e identificar alguns problemas enfrentados pelos docentes. 
As oficinas, aulas culturais e o PIBID desenvolvem temas voltados para a realidade do aluno, para que desperte o interesse em aprender aproximando o estudante do ambiente escolar para que se sinta incluindo no meio social.

O Centro de educação de jovens e adultos é uma modalidade de ensino que atende jovens e adultos fora de idade que não chegaram a frequentar a escola na idade própria. De acordo com a pesquisa, pode-se concluir que, a escola CEJA SILVA FREIRE, busca atender os alunos respeitando suas histórias, cultura, com ênfase na aprendizagem significativa.

Os professores refletem sobre as suas práticas pedagógicas procurando entender as dificuldades dos alunos, valorizando sua história de vida. Através das reflexões é possível se tornar um professor sensível aos acontecimentos das salas de aula e assim com mais facilidade para relacionar os conteúdos científicos com os conhecimentos prévios dos estudantes, despertando no aluno o interesse pelo conhecimento.

A formação dos alunos é para o pensamento crítico, tornando pessoas ativas, participando do meio social para lutar por uma sociedade com igualdade. Uma formação que permita a construção de um mundo melhor.

\section{Referências}

Ajala, Michele Cristina. ALUNO EJA: motivos de abandono e retorno escolar na modalidade EJA e expectativas pós EJA em Santa Helena-PR. Paraná: Medianeira, 2011.

Becker, F. M. Mercado de trabalho e qualificação da força de trabalho no brasil em tempos de globalização contemporânea. Florianópolis, 2012.

Carbone, S. A. B. Dificuldades de aprendizagem na educação de jovens e adultos: uma reflexão com alfabetizadores da EJA. Medianeira, 2013.

Cardoso, D. S. Dificuldades enfrentadas pelos professores de Matemática da educação de jovens e adultos frente a uma metodologia de ensino. Santa Catarina: Criciúma, fevereiro de 2007.

CEJA Silva Freire, Projeto Político Pedagógico escola, 2011.

Freire, P. Livro Pedagogia da Autonomia; Saberes Necessários à Prática Educativa, Editora Paz e Terra S/A, 1996.

Inocencio, A. O., \& Hlenka, V. Principais causas para a desistência de alunos no ensino médio. Revista Eletrônica Científica Inovação e Tecnologia. Medianeira, 8(16), E-4974. Universidade Tecnológica Federal do Paraná (UTFPR).

Nascimento, S. M. Educação de jovens e adultos EJA, na visão de Paulo Freire. Paranavaí, 2013.

Oliveira, M. C., Ponte, V. M. R., Barbosa, J. V. B. Metodologias de pesquisa adotadas nos estudos sobre Blanced Scorecard. XXV Congresso Brasileiro de Custos Minas Gerais: Belo Horizonte, 2006. https://anaiscbc.emnuvens.com.br/anais/article/view/

Pereira, A. S. et al. (2018). Metodologia da pesquisa científica. UFSM. https://repositorio.ufsm.br/bitstream/handle/1/15824/Lic_Computacao_MetodologiaPesquisa-Cientifica.pdf?sequence $=1$.

Silva, M. I. M. S., Guerra, M. J. Os impactos da escolarização tardia na eja: um desafio a ser vencido na vida de adultos das camadas populares. Congresso internacional de educação e inclusão. CINTEDI. Paraíba, 2014. http://www.editorarealize.com.br/revistas/cintedi/anais.php 